UNDERGRADUATE RESEARCH IN NATURAL AND CLINICAL SCIENCE AND TECHNOLOGY (URNCST) JOURNAL Read more URNCST Journal articles and submit your own today at: https://www.urncst.com

\title{
Mechanisms Underlying Exercise-Induced BDNF Stimulated Memory Improvements in Rodents
}

Ananya Jain, BSc Student [1]*

[1] The George Washington University Colombian College of Arts and Sciences, Washington, D.C., USA 20052

*Corresponding Author: ananyajain@gwu.edu

\begin{abstract}
Introduction: Increases in Brain-Derived Neurotrophic Factor (BDNF), are known to be associated with improvements in memory and can be increased by exercise. This suggests that these memory improvements could be induced from exercise associated increases in BDNF in key memory related areas of the brain such as the hippocampus. However, the underlying neurobiology outlining how exercise may affect memory remains elusive. Thus, the focus of this review is to understand the relationship between exercise induced increases in BDNF and memory improvements, and to identify potential pathways of activation that may induce these effects.

Methods: An in-depth literature review was performed to analyze the mechanisms of memory involving exercise induced increases of BDNF in rodents. Both primary and review articles were used, found through Google Scholar, PubMed, and the George Washington University Gelman Library databases, and were found using search terms that included exercise, memory, rodents, and BDNF.

Results: Pathways found to be potentially involved in this mechanism include the TrkB ERK1 pathway, TrkB activation of $\beta$ CaMKII, PI3-K and MAPK pathways, and the BDNF/TrkB/SYN pathway, with the SIRT1/PGC1a/FNDC5 pathway being a potential upstream pathway to induce BDNF activity. It was also found that exercise induced BDNF increases can recover memory impairments in different neurodegenerative states, such as in rodent models of Alzheimer's disease and Down syndrome.

Discussion: The collected studies demonstrate that exercise induced increases in BDNF expression are related to improved memory at least partially due to increased BDNF expression in memory associated brain regions, such as the hippocampus. The underlying neurobiology is still unclear, although potential pathways for this mechanism have been identified.

Conclusion: These results of this review expose avenues of research to better understand the underlying neurobiology of exercise enhanced BDNF effects on memory improvements. The identified link between exercise and memory improvements via exercise induced BDNF increases can be potentially applied and used for future investigations into clinical therapeutic treatments for improving memory through exercise.
\end{abstract}

Keywords: BDNF; rodents; exercise; memory

\section{Introduction}

It is widely known and accepted that regular exercise is highly beneficial for one's health. Exercise stimulates responses in the brain, activating signal cascades that are involved with the central nervous system, including mental processes like memory [1]. Exercise has been shown to increase the levels of Brain-Derived Neurotrophic Factor (BDNF) in rodent brains with increased levels of BDNF and nerve growth factor messenger ribonucleic acid (mRNA), BDNF promoter expression and mature BDNF protein found in the hippocampus and prefrontal cortices, which are important memory associated regions of the brain $[2,3]$. BDNF is a neurotrophin produced in the cortex and is one of the most abundant growth factors in the brain. It has varying functions, which can directly impact the activity of neurons, and is associated with memory function [4]. Initially, it is synthesized in a Pro-BDNF form that has 247 amino acids, then packaged into the secretory vesicles that allow for release of BDNF from neurons. When cleaved proteolytically by metalloproteinases or plasmin outside the neuron, the ProBDNF becomes mature. It can then bind to tropomyosinrelated kinase receptor type $\mathrm{B}$ (TRKB), and the p75 tumor necrosis factor receptor, but mainly to TRKB due to greater expression and higher affinity for this receptor [4].

The correlation between exercise and increased BDNF levels can suggest a link between exercise and improvement in memory performance [5]. It has been shown that the expression of BDNF in the hippocampus and the cortex is impacted by exercise, which may in turn have effects on learning, synaptic plasticity, and neurogenesis [4], all of which are closely tied with memory. It has also been shown through epigenetic study that exercise can positively 
UNDERGRADUATE RESEARCH IN NATURAL AND CLINICAL SCIENCE AND TECHNOLOGY (URNCST) JOURNAL Read more URNCST Journal articles and submit your own today at: https://www.urncst.com

modulate BDNF promote regions and increase overall transcription levels of this neurotrophic factor [6]. Exercise intensity has also been implicated in the beneficial effects of exercise on memory, with increased BDNF pathway activation with increased intensity, and overall improvement in memory performance in a novel object recognition task [7]. In a similar investigation, researchers used a Morris Water Maze (MWM) to test the spatial memory of mice before and after a five-month treadmill exercise program. They found that after the five months of exercising on a treadmill, the mice had significantly lower escape latencies (spent less time escaping the maze) and they also had an improved spatial memory. Immunohistochemistry results also demonstrated that the treadmill exercise resulted in an increase of BDNF positive cells in the cerebral cortex and hippocampus. This implies that the BDNF levels increased by the treadmill exercise could have caused the improvement in spatial memory [8]. Taken together, the data from these studies demonstrate a potential link between exercise induced BDNF increases and memory improvements, as well as providing potential pathways that merit future investigation to explain these improvements.

Additionally, it has also been shown that deficits in BDNF are associated with memory deficits. In a mouse model of Down Syndrome, researchers found that stimulating BDNF through pharmacological means resulted in not only improvements in the plasticity of the synapses but also improvements to memory deficits. Neurodegenerative disorders such as Alzheimer's disease and Down syndrome are associated with memory impairments. Targeting these impairments with BDNF related therapies provides a potential avenue for research into treating the memory impairing effects of neurodegenerative effects, such as Down syndrome, especially with the knowledge that those with Down Syndrome have decreased BDNF in their hippocampus [9]. Stimulation of BDNF signaling may cause improvements in the memory deficits and demonstrate that BDNF signaling stimulation is associated with memory improvements, and then that exercise is associated with increased levels of BDNF which can positively affect memory deficits.

BDNF has been shown to be associated with memory such that increased levels of BDNF are correlated with improved memory. BDNF can also be increased by exercise. As such, a relationship between exercise and memory can be found such that exercise increases BDNF, which in turn has beneficial effects on the memory. Thus, the goal of this paper is to study the ability of exercise to increase BDNF levels in key memory related areas of the brain and observe the effects of these increases on memory related tasks and experiments. The focus is to determine whether exercise induced BDNF increases are responsible for memory improvements, and to investigate a possible pathway via which these improvements may occur through a BDNF associated pathway.

\section{Methods}

An in-depth literature review was performed to gain understanding of the mechanisms of memory formation and retention involving exercise and BDNF. Studies were analyzed to investigate the physiologic effects of exercise on the brain, and specifically on the areas of the brain that are involved with memory recall such as the hippocampus and prefrontal cortex. Fifteen articles were compared to draw conclusions on the effects of exercise on memory retention. Search terms used to find articles included exercise, memory, rodents, and BDNF. Primary and review articles were found through Google Scholar, PubMed, and the George Washington University Gelman Library databases, with publication dates from 1996 to the present year.

\section{Results}

Exercise Induced BDNF Pathways and Memory Improvements

BDNF activation is associated with memory via numerous potential pathways. A study using Wistar rats suggests that exercise-induced improvements in spatial memory occur through a TrkB associated pathway. It was proposed that short term effects of BDNF activation of this pathway due to exercise, results in upregulation and release of synaptic vesicle proteins associated with memory processing. It was also found that injection of BDNF into the left ventricle activated granule cell TrkB receptors, mimicking the pathway activations induced by exercise. Therefore, this study concluded that exercise improved spatial learning and memory by means of exercise induced BDNF in the dentate gyrus, activating the TrkB-ERK1 (Extracellular signal-regulated protein kinase 1) pathway to increase synaptic transmission and plasticity (Figure 1) [10].

Another potential pathway implicated in exercise induced BDNF's ability to cause improvements in memory involves TrkB's activation of $\beta$-CaMKII $(\beta$ $\mathrm{Ca}^{2+} /$ calmodulin-dependent protein kinase II). Cassilhas et. al. performed a study investigating male Wistar rats with and without either aerobic or resistance exercise, and tested spatial memory using an MWM task. Animals in control groups were compared to those in either resistance exercise with a vertical ladder or aerobic exercise with a treadmill. Animals in both the aerobic exercise as well as the resistance exercise groups were found to have spent less time and swam a shorter distance to reach the escape platform quadrant as compared with the control group, showing enhanced spatial memory. BDNF in the hippocampus was measured with an Enzyme-linked immunoassay (ELISA), and western blot analysis was performed. It was found that the aerobic exercise group had increased levels of IGF-1 (Insulin-like growth factor-1), BDNF, TrkB, and $\beta$-CaMKII in the hippocampus, causing an increase in synapsin 1 and synaptophysin expression. TrkB activation of $\beta$-CaMKII may be implicated in the role of exercise induced BDNF on improved memory (Figure 1). This study also investigated 
UNDERGRADUATE RESEARCH IN NATURAL AND CLINICAL SCIENCE AND TECHNOLOGY (URNCST) JOURNAL Read more URNCST Journal articles and submit your own today at: https://www.urncst.com

resistance exercise by having the rats climb a vertical ladder with progressively heavier weight loads attached to the rats' tails and found that this type of exercise did not actually correlate with increased BDNF levels, but rather increased IGF-1 serum levels [11].

Additionally, other pathways that may be implicated in exercise induced BDNF and its role on memory involve PI3 (Phosphoinositide 3) and MAP (Mitogen-activated protein) kinases, which have been shown to be associated with BDNF-dependent memory and learning as NMDA (N-methyl-D-aspartate) and non-NMDA receptors and presynaptic exocytosis proteins can be targeted by BDNF/TrkB signaling. It was seen that BDNF binding to TrkB receptors resulted in the activation of PI3 and MAP kinase pathways, phosphorylation of NMDA receptors, increases in neurotransmitter releases at presynaptic sites, and increased protein synthesis (Figure 1), all of which may be implicated in the role of exercise induced BDNF in memory improvements [12].

Furthermore, lactate-dependent pathways may also be implicated in the role of BDNF on exercise induced memory improvements. Inhibition of the lactate transporter results in no exercise induced increase in Bdnf promoter I, which is normally observed in the mice after exercise when the lactate transporter is functional [13]. Researchers further found that injecting mice with lactate significantly increased hippocampal Bdnf promoter I expression, BDNF protein levels, TRKB phosphorylation, and synaptic plasticity gene levels, demonstrating the activation of BDNF signaling pathways. Exploring the effects of this pathway activation on memory, intraperitoneal injection of lactate resulted in improved memory recall in a MWM experiment paradigm compared to controls. Contrastingly, mice injected with lactate and a TRK (Tropomyosin receptor kinase) inhibitor did not demonstrate these improvements. It was also found that lactate entering the brain increases protein SIRT-1 and that Sirt-1 knockdown resulted in no lactate mediated Bdnf induction. Furthermore, via Western blot analysis, it was observed that lactate injection activates the SIRT1 (Sirtuin 1)/PGC1a (Peroxisome proliferator-activated receptor gamma coactivator 1 alpha)/FNDC5 (Fibronectin type III domain-containing protein 5) pathway to induce hippocampal BDNF expression (Figure 1) [13].

Overall, increasing BDNF by exercising appears to be associated with improved memory function and decreased hippocampal dysfunction [14]. There are a variety of pathways involving exercise induced BDNF activation of TrkB that have been shown to potentially result in memory improvements. Additionally, there is a potential involvement of the SIRT1/PGC1a/FNDC5 pathway in the induction of BDNF expression (Figure 1).
Exercise Induced Increase BDNF Levels can Retrieve Memory Deficits

BDNF has been shown to be able to improve on memory deficits that occur because of disease states. Alzheimer's disease is known to be associated with BDNF deficiencies and increases in BDNF have been shown to be associated with memory improvements [4]. Xiong et. al. has demonstrated that showed the effects of long-term treadmill exercise on spatial memory by regulation of BDNF expression and microglial activation. 18 transgenic Alzheimer's Disease mice were divided into a relatively sedentary control group and an exercise group in which mice ran on a treadmill. The exercise regimen was six days per week for five months, starting at $70 \mathrm{~m}$ per day at five to eight $\mathrm{m} / \mathrm{min}$ and increased up to $300 \mathrm{~m}$ per day at $10-15 \mathrm{~m} / \mathrm{min}$ at the end of the first month, at which time the running distance remained constant for the rest of the months. After the exercise period, a MWM test and immunohistochemical detection were performed. It was found that sedentary Alzheimer's mice in the control group had longer escape latency than wild type mice, and these mice spent the same amount of time in the quadrants with and without the platform in the pool. However, exercise Alzheimer's mice spent more time in the quadrant of the pool with the platform, indicating enhanced memory recall. Furthermore, the exercise group had great BDNF positive cells in the cerebral cortex and hippocampus compared to the sedentary group [8].

Another neurodegenerative disease that causes memory deficits is Down syndrome. A study on aerobic exercise and BDNF therapy was found to rescue learning and memory in a mouse model of Down syndrome. Male mice were given access to running wheels for four weeks, and control mice were housed in cages without running wheels. Contextual fear conditioning was used to test associative memory, with the control group demonstrating memory impairments by having lessened freezing responses that demonstrated decreased abilities in associative learning, which was fully recovered following exercise, as shown in the exercise group. Object location test was also used to evaluate spatial memory. After twenty-four hours, the sedentary Down syndrome mice were unable to identify the new location of a familiar object, but after four weeks of exercise, the performance of this group was equal to that of the wild type group. NOR test was also used to evaluate long term memory, and the sedentary Down syndrome mice were unable to discriminate the new object, while the exercise group performed significantly similarly to the wild type mice, such that four weeks of exercise were sufficient to rescue the novelty discrimination deficits seen in the Down syndrome model mice. Through an ELISA and immunoblot quantification, aerobic exercise was shown to result in upregulation of BDNF in both wild type mice and Down syndrome mice. Real time quantitative Polymerase chain 
UNDERGRADUATE RESEARCH IN NATURAL AND CLINICAL SCIENCE AND TECHNOLOGY (URNCST) JOURNAL Read more URNCST Journal articles and submit your own today at: https://www.urncst.com

reaction (PCR) results showed that transcription enhancement in the same BDNF transcripts resulted in the exercise-induced increases in BDNF observed in both the wild type and Down syndrome model mice [9]. Overall, it is observed that exercise induced increases in BDNF can recover memory impairments across different neurodegenerative states, such as in the cases of Alzheimer's disease and Down syndrome.

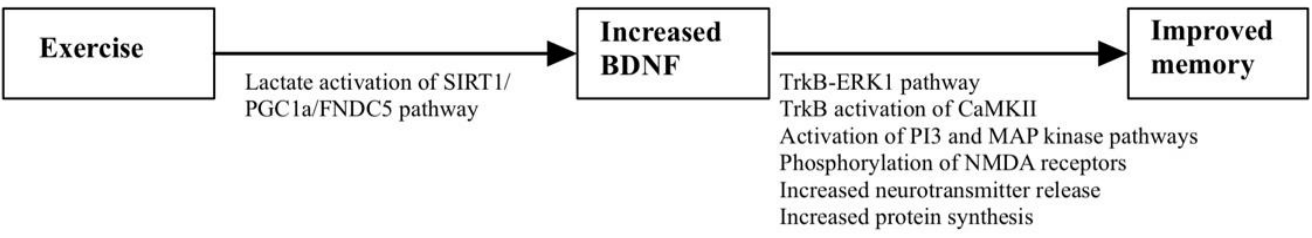

Figure 1. Possible mechanism pathways between exercise leading to memory improvements through increases of BDNF in the hippocampus.

\section{Discussion}

This investigation explored how exercise can improve memory, through the increased expression of BDNF, a neurotrophin that has been shown to have links to improved memory. It was found that increased expression of BDNF in the hippocampus, frontal cortex, and caudal cortex, occurs after physical exercise and activity [2,3,7,8,11]. From baseline levels of BDNF, the significant increases observed in these brain regions after exercise show a clear positive relationship between exercise and BDNF levels in these areas of the brain, potentially through a TrkB related pathway [7]. These region-specific increases in BDNF could implicate exercise associated effects on memory $[2,4,8,15]$.

\section{Exercise Induced Increases of BDNF Positively Affect} Memory in Rodents

Studies investigating the link between exercise induced increases in BDNF and memory corroborated the results found linking exercise with BDNF increases in the hippocampus, prefrontal cortex, and cerebral cortex with memory improvements, as well as finding improved memory with increased levels of exercise. When rats were treated with low or high intensity exercise, those that had higher intensity exercise had the greatest memory improvements on a novel object recognition task and higher activation of the BDNF pathway. Furthermore, an experiment investigating performance on a MWM test as well as immunohistochemical detection of BDNF positive cells found that Alzheimer's model mice that underwent exercise had improved performance on the maze than those that were sedentary, and also had more BDNF positive cells in the cerebral cortex and hippocampus. This suggests that BDNF increases in key memory related brain regions is responsible, at least in part, for the beneficial effects of exercise on memory $[7,8]$.

Several pathways were found to be potentially involved in facilitating the memory improvements that are seen as a result of exercise induced BDNF increases [7,13]. These pathways are significant due to their mutual connection to exercise induced BDNF and all involve memory related functions by either affecting key memory related areas of the brain such as the hippocampus, or affecting the brain in ways that impact memory, such as through increasing plasticity $[7,13]$. It was found that the activation of BDNF due to exercise may be associated with lactate via a SIRT1/PGC1a/FNDC5 pathway [13]. This provides insight into how exercise induced increases in lactate will result in activation of pathways that increase BDNF, which in turn can improve memory. This study also indicated that the increased lactate levels in the blood and hippocampus are associated with induction of Bdnf and other like synaptic plasticity genes to improve memory by demonstrating the lack of improved memory in those mice with lactate and TRK inhibitors [7,13].

Pathways that involve the downstream effects of exercise induced BDNF include the BDNF/TrkB/SYN (Synuclein) pathway with activation in the hippocampus and less activation in the frontal cortex [7]. These are regions that are known to be implicated in memory, especially the hippocampus. Also potentially implicated is the BDNF TrkB pathway involving ERK1 to increase synaptic transmission and plasticity [10]. Synaptic transmission and plasticity may be involved in the formation and therefore the retention and recall of memory. TrkB may also be involved in activation of $\beta$-CaMKII in the hippocampus [11]. As mentioned before, activation in the hippocampus, a region known to be heavily involved in memory, may provide insight into a mechanism for memory improvement. Additional pathways that may be involved are pathways with PI3-K (Phosphoinositide 3 kinase) and MAPK (Mitogen-activated protein kinase) signaling [12]. It was also found that different forms of exercise, such as aerobic exercise versus resistance training exercise, resulted in differing molecular mechanisms, with aerobic activity being associated with the BDNF TrkB pathway while resistance exercise resulted in increased IGF1 serum levels. This demonstrates that different forms of exercise may affect memory in different ways. As such, they may also affect disease state memories differently, demonstrating a need for further study into variants of exercise and their mechanisms of pathway activations that 
UNDERGRADUATE RESEARCH IN NATURAL AND CLINICAL SCIENCE AND TECHNOLOGY (URNCST) JOURNAL Read more URNCST Journal articles and submit your own today at: https://www.urnest.com

affect memory in order to investigate the possibility of creating therapeutic treatments for memory impairments that may occur as a result of different neurodegenerative and memory-affecting conditions [11].

\section{Exercise Induced BDNF Increases and Memory in}

Neurodegenerative Disease Rodent Models

BDNF has also been investigated with regards to memory deficits. In a mouse model of Down syndrome, it was found that BDNF stimulation recovered memory deficits. Additionally, while those with Down syndrome have decreased levels of hippocampal BDNF, after exercising these levels increased BDNF expression. The mice were tested on associative memory using contextual fear conditioning, and exercise fully allowed for the restoration of impaired memory in Down syndrome mice. Additionally, in a test of spatial memory using an object location test, the exercise group Down syndrome mice performed equal to wild type mice while when sedentary, the Down syndrome mice were unable to perform as well on the task. A novel object recognition task also demonstrated exercise induced memory improvements with exercise group Down syndrome mice performing better than sedentary ones, at a level similar to the wild type mice [9]. These data further demonstrate the mechanism between exercise increasing BDNF levels and this increase resulting in memory improvements [7-9]. Studies similar to those such as Cefis et. al., provides a potential mechanism by means of a $\mathrm{BDNF} / \mathrm{TrkB} / \mathrm{SYN}$ pathway that may be involved in the increased BDNF levels as a result of exercise, which then improves memory. The same gene transcripts were seen in both wild-type and disease state mice, demonstrating a genetic link to memory [7]. These results investigating exercise induced BDNF recovery of memory deficits may also be linked to other memory associated neurodegenerative diseases and conditions, not only Down syndrome and Alzheimers, but other conditions such as Parkinson's, and schizophrenia, and perhaps even to the memory impairments seen in some individuals with mental health disorders and conditions such as depression, anxiety disorder, and chronic stress. Studies on how these conditions may be improved using exercise could be further investigated in clinical trials with a focus on BDNF levels and their association with any observed memory deficit improvements.

Overall, the data demonstrate that exercise increases expression of BDNF, and BDNF increases are correlated to improved memory, such that the effects of exercise on memory improvement are directly occur at least partially as a result of increased BDNF expression in areas of the brain such as the hippocampus, prefrontal cortex, and frontal cortex. Although this is a consistent finding, the underlying neurobiology remains elusive. However, these results are significant in that they expose an avenue for future research to fully parse out the neurobiology of exercise enhanced BDNF effects on memory improvements.
Despite this gap, it can be suggested that there are potential therapeutic benefits of exercise as an exogenous treatment alternative for memory deficits, and that exercise regimens can contribute to improved memory.

\section{Conclusions}

Overall, this study demonstrated that exercise results in increased expression of BDNF in brain regions that are known to be associated with memory. It has been confirmed that exercise increases BDNF expression, and that this increase contributes, in part, to the improved memory seen due to exercise. This correlation was further confirmed by demonstrating the ability of exercise induced BDNF increases on rescuing memory deficits in a Down syndrome mouse model. These results demonstrate that exercise can be used to aid in the improvement of memory, even potentially in cases of memory deficits caused by conditions such as Down syndrome. It also opens an avenue for research into exercise used alongside therapeutic treatments to target BDNF in areas of the brain such as the hippocampus, prefrontal cortex, caudal cerebral cortex, and frontal lobe.

Questions remain about the underlying neurobiology and mechanisms that contribute to the effects of exercise induced increases in BDNF on memory, and further investigation needs to be performed on the TrkB associated signaling pathway to determine exactly how this pathway may influence memory. As this investigation was on rodent models, future studies may focus on targeting the correlation between BDNF increases due to exercise and memory improvements in humans. Branching off this, more research may also be performed in the future to determine how exercise can affect memory via BDNF involvement in humans, and how different exercise regimens may affect different aspects of memory such as memory retention, formation, and recall. Investigations can delve into the possibility of the use of exercise as a form of clinical treatment in improving memory and in treating memory deficits.

\section{List of Abbreviations Used}

BDNF: brain-derived neurotrophic factor

MWM: Morris water maze

NOR: novel object recognition

mRNA: messenger ribonucleic acid

ELISA: enzyme-linked immunoassay

PCR: polymerase chain reaction

IGF-1: insulin-like growth factor-1

MAP: mitogen-activated protein

MAPK: mitogen-activated protein kinase

PI3: phosphoinositide 3

PI3-K: phosphoinositide 3 kinaseNMDA: N-methyl-Daspartate

TRKB: tropomyosin receptor kinase $\mathrm{B}$

$\beta$-CaMKII: $\beta \mathrm{Ca}^{2+} /$ calmodulin-dependent protein kinase II 
UNDERGRADUATE RESEARCH IN NATURAL AND CLINICAL SCIENCE AND TECHNOLOGY (URNCST) JOURNAL Read more URNCST Journal articles and submit your own today at: https://www.urncst.com

SIRT1: sirtuin 1

PGC1a: peroxisome proliferator-activated receptor gamma coactivator 1 alpha

FNDC5: fibronectin type III domain-containing protein 5

TRK: tropomyosin receptor kinase

SYN: synuclein

ERK1: extracellular signal-regulated protein kinase 1

\section{Conflicts of Interest}

The author declares that they have no conflict of interests.

\section{Ethics Approval and/or Participant Consent}

The study performed was a review and did not require ethics approval and/or participant consent.

\section{Authors' Contributions}

AJ: study design and planning, reviewed and analyzed data, drafted and edited the manuscript. and gave final approval of the version to be published.

\section{Acknowledgements}

I would like to acknowledge Bi-ru Amy Yeung for guidance in research and structuring the manuscript, and editing and writing assistance. Figure 1 was created using Notability software.

\section{Funding}

This study was not funded.

\section{References}

[1] Stroth S, Hille K, Spitzer M, Reinhardt R. Aerobic endurance exercise benefits memory and affect in young adults. Neuropsychological Rehabilitation. 2009;19(2):223-43. https://doi.org/10.1080/09602010802091183

[2] Neeper SA, Gómez-Pinilla F, Choi J, Cotman CW. Physical activity increases mRNA for brain-derived neurotrophic factor and nerve growth factor in rat brain. Brain Research. 1996;726(1-2):49-56. https://doi.org/10.1016/0006-8993(96)00273-9

[3] Sleiman SF, Henry J, Al-Haddad R, el Hayek L, Haidar EA, Stringer T, et al. Exercise promotes the expression of brain derived neurotrophic factor (BDNF) through the action of the ketone body $\beta$ - hydroxybutyrate. eLife. 2016;5:1-21. https://doi.org/10.7554/eLife.15092

[4] Nagahara AH, Tuszynski MH. Potential therapeutic uses of BDNF in neurological and psychiatric disorders. Nature Reviews Drug Discovery. 2011;10(3):209-19. https://doi.org/10.1038/nrd3366

[5] Loprinzi PD, Frith E. A brief primer on the mediational role of BDNF in the exercise-memory link. Clinical Physiology and Functional Imaging. 2019;39(1):9-14. https://doi.org/10.1111/cpf.12522
[6] Leraci A, Mallei A, Musazzi L, Popoli M. Physical exercise and acute restraint stress differentially modulate hippocampal brain-derived neurotrophic factor transcripts and epigenetic mechanisms in mice. Hippocampus. 2015;25(11):1380-92. https://doi.org/10.1002/hipo.22458

[7] Cefis M, Prigent-Tessier A, Quirié A, Pernet N, Marie $\mathrm{C}$, Garnier P. The effect of exercise on memory and BDNF signaling is dependent on intensity. Brain Structure and Function. 2019;224(6):1975-85. https://doi.org/10.1007/s00429-019-01889-7

[8] Xiong JY, Li SC, Sun YX, Zhang XS, Dong ZZ, Zhong $\mathrm{P}$, et al. Long-term treadmill exercise improves spatial memory of male APPswe/PS1dE9 mice by regulation of BDNF expression and microglia activation. Biology of Sport. 2015;32(4):295-300. https://doi.org/10.5604/20831862.1163692

[9] Parrini M, Ghezzi D, Deidda G, Medrihan L, Castroflorio E, Alberti M, et al. Aerobic exercise and a BDNF-mimetic therapy rescue learning and memory in a mouse model of Down syndrome. Scientific Reports. 2017;7(1):1-22. https://doi.org/10.1038/s41598-01717201-8

[10] Bechara RG, Lyne R, Kelly ÁM. BDNF-stimulated intracellular signaling mechanisms underlie exerciseinduced improvement in spatial memory in the male Wistar rat. Behavioural Brain Research. 2014;275:297-306. http://doi.org/10.1016/j.bbr.2013.11.015

[11] Cassilhas RC, Lee KS, Fernandes J, Oliveira MGM, Tufik S, Meeusen R, et al. Spatial memory is improved by aerobic and resistance exercise through divergent molecular mechanisms. Neuroscience. 2012;202:30917. https://doi.org/10.1016/j.neuroscience.2011.11.029

[12] Yamada K, Nabeshima T. Current perspective brainderived neurotrophic factor/TrkB signaling in memory processes. Journal of Pharmocological Sciences. 2003;91:267-70. https://doi.org/10.1254/jphs.91.267

[13] el Hayek L, Khalifeh M, Zibara V, Abi Assaad R, Emmanuel N, Karnib N, et al. Lactate mediates the effects of exercise on learning and memory through SIRT1-dependent activation of hippocampal brainderived neurotrophic factor (BDNF). Journal of Neuroscience. 2019;39(13):2369-82. https://doi.org/10.1523/JNEUROSCI.1661-18.2019

[14] Kirk I. Erickson, Destiny L. Miller and KAR. The aging hippocampus: Interactions between exercise, depression, and BDNF. Bone. 2008;23(1):1-7. https://doi.org/10.1177/1073858410397054

[15] Preston AR, Eichenbaum H. Interplay of hippocampus and prefrontal cortex in memory. Current Biology. 2013;23(17):R764-73. https://doi.org/10.1016/j.cub.2013.05.041 
UNDERGRADUATE RESEARCH IN NATURAL AND CLINICAL SCIENCE AND TECHNOLOGY (URNCST) JOURNAL

Read more URNCST Journal articles and submit your own today at: https://www.urncst.com

\section{Article Information}

Managing Editor: Jeremy Y. Ng

Peer Reviewers: Bi-ru Amy Yeung, John Johnson

Article Dates: Received Jun 26 21; Accepted Aug 04 21; Published Sep 1021

\section{Citation}

Please cite this article as follows:

Jain A. Mechanisms underlying exercise-induced BDNF stimulated memory improvements in rodents. URNCST Journal.

2021 Sep 10:5(9).

https://urncst.com/index.php/urncst/article/view/298

DOI Link: https://doi.org/10.26685/urncst.298

\section{Copyright}

(C) Ananya Jain. (2021). Published first in the Undergraduate Research in Natural and Clinical Science and Technology (URNCST) Journal. This is an open access article distributed under the terms of the Creative Commons Attribution License (https://creativecommons.org/licenses/by/4.0/), which permits unrestricted use, distribution, and reproduction in any medium, provided the original work, first published in the Undergraduate Research in Natural and Clinical Science and Technology (URNCST) Journal, is properly cited. The complete bibliographic information, a link to the original publication on http://www.urncst.com, as well as this copyright and license information must be included.
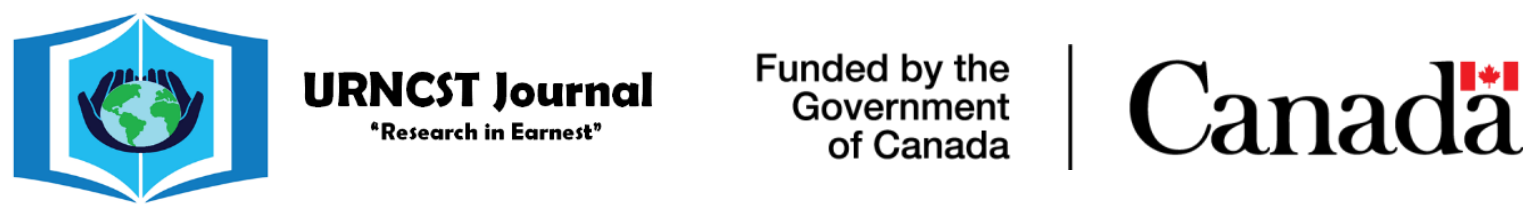

Do you research in earnest? Submit your next undergraduate research article to the URNCST Journal!

| Open Access | Peer-Reviewed | Rapid Turnaround Time | International | | Broad and Multidisciplinary | Indexed | Innovative | Social Media Promoted |

Pre-submission inquiries? Send us an email at info@ urncst.com | Facebook, Twitter and LinkedIn: @URNCST

Submit YOUR manuscript today at https://www.urncst.com/! 